\title{
HIV/AIDS related knowledge among antiretroviral therapy clients at Kathmandu and Dhulikhel, Nepal: A cross sectional study
}

\author{
Sweta Shrestha ${ }^{1 *}$, \\ Badri KC1, \\ Yushma Shrestha ${ }^{1}$, \\ Rabina KC 1 , \\ Sudikshya Dhanju ${ }^{1}$, \\ Punam Khadka ${ }^{1}$, \\ Sayara Khwaunju ${ }^{1}$ \\ ${ }^{1}$ Department of Pharmacy, School of Science,
Kathmandu University, Dhulikhel, Kavre,
Nepal
}

*Corresponding author:

Sweta Shrestha

sweta.shrestha@ku.edu.np

Keywords:

Knowledge; HIV/AIDS;

Antiretroviral therapy; Nepal

https://www.pharmacy.mahidol.ac.th/journal/ (C) Faculty of Pharmacy, Mahidol University (Thailand) 2021

\begin{abstract}
Clients' knowledge of HIV/AIDS is identified as one of the key factors strongly associated with higher risk of non-adherence. However, accurate data on knowledge of HIV/AIDS among the clients visiting ART sites in Nepal are lacking. This study aims to investigate the knowledge of ART clients on HIV/AIDS. A crosssectional survey of 69 ART clients visiting five different ART clinics was done using interviewer-administered questionnaire. Patients who answered $\geq 9$ answers correctly $(\geq 75 \%)$ were categorized under adequate knowledge and those who answered $<9$ questions correctly $(<75 \%)$ were categorized under inadequate knowledge. Majority of the clients $(n=67,98.5 \%)$ possessed an inadequate knowledge about HIV/AIDS. Of total, $76.8 \%$ believed that HIV/AIDS could possibly be a hereditary disease, $91.3 \%$ presumed about the existence of a vaccine for the disease, $66.7 \%$ were unaware about breastfeeding being a viable way of transmitting the virus. Erroneous understanding of the term 'window period' and its duration was seen in $64.4 \%$ respondents. None of the participants were aware of the term 'viral load' and the methods of measuring it. Only $33.3 \%$ and $17.3 \%$ rightly mentioned the action to be taken in case of missed dose and running out of prescription for ART medications, respectively. The results suggest a dire need for a comprehensive educational approach for the ART clients on HIV/AIDS and their medication regimens.
\end{abstract}

\section{INTRODUCTION}

Advent of antiretroviral drugs is a revolutionary triumph that has transfigured HIV/AIDS into a chronic manageable disease bringing a substantial decline in HIV related mortality. Adequate suppression of viral replication and delayed disease progression can be measurably achieved with the highly active antiretroviral therapy (HAART). However, strict adherence to the ART is a mandatory prerequisite to gain such clinical benefits. Adherence to less than $95 \%$ of the prescribed doses have resulted into inadequate suppression of HIV viral load, a marginal increase in CD4 count and a potential risk of developing drug resistance ${ }^{1-6}$. Lack of knowledge of the basic concepts of HIV and the medication regimens has been recognized as one of the key factors associated with higher risk of non-adherence among HIV patients, ${ }^{4,6,7}$.

Lack of HIV/AIDS knowledge gives rise to incorrect HIV/AIDS beliefs, strengthened by cultural and religious outlooks negatively influencing ART adherence ${ }^{7}$. Hence it becomes imperative to investigate patients' knowledge and perception about HIV as it may influence their adherence to the therapy and their consequential 
clinical status. This cross sectional study was initiated considering the paucity of information with regard to the knowledge of HIV patients in the country.

\section{MATERIALS AND METHODS}

\subsection{Study design and site}

A descriptive cross-sectional study was conducted at five ART sites of Nepal covering three districts of the country. The ART sites approached for data collection were ART clinic of Tribhuvan University Teaching Hospital (TUTH), Maharajgunj, Kathmandu; Maiti Nepal; Dhulikhel Hospital; Sparsha Nepal; and Teku Hospital. A total of 69 patients on ART were randomly interviewed and the study was conducted from May to October 2016.

\subsection{Study population}

Patients >18-year-old who were on ART for at least three months and who were willing to participate in the study were included in the study. Participants on ART with coexisting condition of substance abuse, pregnant women, pediatrics and patients admitted to the hospital were excluded.

\subsection{Study tools}

Questionnaire assessing the participants' sociodemographic characteristics, knowledge on the basic concepts of HIV and side effects of ART was designed, based on the previously published literatures ${ }^{2,8,9}$. The questionnaire was pretested in ten clients visiting the ART sites and necessary modification was done on the questionnaire.

\subsection{Data collection and analysis}

Patients who came to the centre for their medications and who met the eligibility criteria were requested for their participation in the study. Verbal consent was sought from the patients and before interviewing. Each correct answer was scored 1 and an incorrect answer was scored 0 . Patients who answered $\geq 9$ answers correctly $(\geq 75 \%)$ were categorized as persons with adequate knowledge and those who answered $<9$ questions correctly $(<75 \%)$ were categorized as persons with inadequate knowledge. The aforementioned threshold of $75 \%$ was chosen on the basis of a published literature by Eugene et al. ${ }^{10}$

Data were analyzed using the Statistical Package for Social Sciences (SPSS) version 25. Chi square test was used to find the association between knowledge score and education, occupation and gender. Pearson correlation test was used to find the relationship between knowledge score and age at $95 \%$ confidence interval. Site-wise comparison of patients' knowledge was done using one-way ANOVA (Analysis of Variance). Furthermore, effect of the HAART on CD4 count and body weight was assessed using independent t test.

\section{RESULTS}

\subsection{Respondents' knowledge of HIV/AIDS}

In a comparative analysis (Table 1), adequate knowledge was higher among clients aged between 34 to 43 years $(2.8 \%)$. Males represented the overall study population with adequate knowledge ( $2.8 \%$ male vs 0 female). Literate clients had adequate knowledge as compared to the illiterate ones ( $14.2 \%$ vs $0 \%)$ and this difference was statistically significant $(\mathrm{p}<0.05)$.

Of 69 patients, only $2.8 \%(n=2)$ were able to answer at least nine out of 12 questions correctly whereas majority of the study population $(\mathrm{n}=67,98.5 \%)$ possessed an inadequate level of knowledge on HIV/AIDS. None of the patients were able to answer all the questions correctly.

Misconception about HIV/AIDS as a hereditary disease persisted among a greater proportion of participants (76.8\%). Only $23.1 \%$ believed that HIV/AIDS was not a hereditarily transmitted disease. Quite interestingly, a majority of the clients presumed that vaccines were available for prevention and control of HIV/AIDS (91.3\%). In regard to the mode of transmission of the disease, a maximal percentage believed unsafe sex $(34.7 \%)$ as the prime mode followed by blood transfusion $(24.6 \%)$, sharing of needles $(21.7 \%)$ and mother-to-child transmission (11.5\%). Only $7.2 \%$ opined that HIV/AIDS could not be transmitted by any of the aforementioned routes. The fact that HIV/AIDS can be transmitted from an infected breastfeeding mother to her child was agreed upon by a lower percentage of the patients (33.3\%). A majority of the patients erroneously understood the term 'window period' as an interval 
during which HIV can be seen in the blood $(65.2 \%)$. Furthermore, duration of window period was incorrectly stated as upto one month by $63.7 \%$. None of the participants were aware of the term 'viral load' and a majority wrongly defined it as the number of infected cells (71\%) and the number of fighter cells (28.9\%) in the blood. When asked about the methods of measuring the viral load, none could mention all the three methods; PCR (Polynerase chain reaction), bDNA (Branched DNA assay), NASBA (Nucleic acid sequence based amplification) as the possible means of measurement. The majority of the patients held a positive opinion on their children not being HIV positive (55\%). When asked about the action to be taken in case of missed dose, only $33.3 \%$ rightly mentioned to take the missed dose only if it was not near the time of next dose. Hypersensitivity reaction with respiratory symptoms was reported by only $30.4 \%$ as a condition requiring emergency visit while on ARV medication. In case of running out of prescription for ARV medication, only $17.3 \%$ mentioned asking for refills for that day so as not to miss the dose, as the right step to be taken.

Table 1. Extent of influence of sociodemographic characteristics on knowledge level.

\begin{tabular}{|c|c|c|c|}
\hline \multirow[t]{2}{*}{ Study variables } & \multicolumn{2}{|c|}{ Knowledge level } & \multirow[t]{2}{*}{ P value } \\
\hline & $\begin{array}{c}\text { Adequate } \\
\text { n }(\%)\end{array}$ & $\begin{array}{c}\text { Inadequate } \\
\text { n(\%) }\end{array}$ & \\
\hline \multicolumn{4}{|l|}{ Age } \\
\hline$\leq 23$ & $0(0)$ & $2(1)$ & \\
\hline $24-33$ & $0(0)$ & $21(1)$ & \\
\hline $34-43$ & $2(5.8 \%)$ & $32(94.1)$ & 0.601 \\
\hline $44-53$ & $0(0)$ & $10(1)$ & \\
\hline $54+$ & $0(0)$ & $2(1)$ & \\
\hline \multicolumn{4}{|l|}{ Gender } \\
\hline Male & $2(4.5 \%)$ & $42(95.4)$ & \\
\hline Female & $0(0)$ & $25(1)$ & 0.745 \\
\hline \multicolumn{4}{|l|}{ Education } \\
\hline Illiterate & $0(0)$ & $3(1)$ & \\
\hline Literate & $0(0)$ & $24(1)$ & \\
\hline Primary level & $1(6.6)$ & $14(93.3)$ & \\
\hline Secondary level & $0(0)$ & $19(1)$ & \\
\hline Higher secondary level & $0(0)$ & $7(1)$ & 0.000 \\
\hline Bachelor level & $1(1)$ & $0(0)$ & \\
\hline \multicolumn{4}{|l|}{ Occupation } \\
\hline Agriculture & $0(0)$ & $27(1)$ & \\
\hline Job holder & $1(20)$ & $4(80)$ & \\
\hline Hotel & $0(0)$ & $4(1)$ & \\
\hline Army & $0(0)$ & $1(1)$ & \\
\hline NGO & $1(3.7)$ & $26(96.2)$ & \\
\hline Driver & $0(0)$ & $2(1)$ & 0.527 \\
\hline Business & $0(0)$ & $3(1)$ & \\
\hline
\end{tabular}

Furthermore, the patients were asked the name of the medicine they were taking and its dose, frequency and time of administration. All the participants were able to recall the frequency and administration time of their ART medication. Only $8.7 \%$ of patients from TUTH were aware of the dose of the medicine they were taking. The name of the medicine could be correctly stated by all the participants from ART site at Dhulikhel Hospital while the percentage varied among the other sites (26\% TUTH, 40\% Maiti Nepal, 40\% Sparsha Nepal) (Table 2).

Table 2. Response to medication regimen. (correct answer)

\begin{tabular}{lcccc}
\hline Site & Medicine name & Frequency & $\begin{array}{c}\text { Dose } \\
\mathbf{n}(\boldsymbol{\%})\end{array}$ & Administration time \\
\hline TUTH & $6(26)$ & $23(100)$ & $2(8.7)$ & $23(100)$ \\
Dhulikhel Hospital & $9(100)$ & $9(100)$ & 0 & $9(100)$ \\
Maiti Nepal & $2(40)$ & $5(100)$ & 0 & $5(100)$ \\
Sparsha Nepal & $2(40)$ & $5(100)$ & 0 & $5(100)$ \\
Teku Hospital & $12(45)$ & $27(100)$ & $1(5)$ & $27(100)$ \\
\hline
\end{tabular}




\subsection{Site-wise comparison of respondents' knowledge}

Significant difference in respondents' knowledge was seen among the ART sites $(\mathrm{p}=0.003)$. Results of the pairwise comparison is presented in Table 3, which shows that respondents in TUTH and Sparsa Nepal had a significantly higher level of knowledge on HIV/AIDS than those visiting Teku Hospital.

Table 3. Pairwise comparison of respondents' knowledge.

\begin{tabular}{lc}
\hline \multicolumn{1}{c}{ Site } & P value \\
\hline TUTH vs Maiti Nepal & 0.1244 \\
TUTH vs Dhulikhel & 0.7440 \\
TUTH vs Teku* & 0.0010 \\
TUTH vs Sparsha Nepal & 0.6647 \\
Maiti Nepal vs DHulikhel & 0.1698 \\
Maiti Nepal vs Teku & 0.7889 \\
Maiti Nepal vs Sparsha Nepal & 0.0285 \\
Dhulikhel vs Teku & 0.0051 \\
Dhulikhel vs Sparsha Nepal & 0.9052 \\
Teku vs Sparsha Nepal* & 0.0020 \\
\hline${ }^{*}$ Pvalue <0.05 &
\end{tabular}

\subsection{Distribution of adverse effects among HAART users}

A total of $33.3 \%$ gave an account of confronting the following adverse effects: nightmares (23.07\%), allergy (23.07\%), backache $(15.38 \%)$, anemia $(15.38 \%)$, nausea and vomiting (7.69\%), blackening of nail (7.69\%), and anorexia (7.69\%).

\subsection{Effect of HAART on body weight and CD4 count}

A statistically significant increase in body weight as well as CD4 count was observed six months after initiation of ART $(\mathrm{p}=0.000)$. Switching of the therapy was done if the CD4 count did not increase after 6 months (Table 4).

Table 4. Alteration in body weight and CD4 count after ART.

\begin{tabular}{lccccc}
\hline Study variables & $\mathbf{n}$ & $\begin{array}{c}\text { Mean value } \\
( \pm \text { SE Mean })\end{array}$ & SD & t-value & P-value \\
\hline Weight (before therapy) & 69 & $51.87( \pm 0.966)^{*}$ & 10.94 & -2.575 & 0.000 \\
Weight (after therapy) & 69 & $55.06( \pm 0.966)^{*}$ & 10.09 & & 0.000 \\
\hline CD4(before therapy) & 69 & $135.56( \pm 10.21)^{* *}$ & 106.62 & -4.878 & \\
CD4(after therapy) & 69 & $343.32( \pm 41.63)^{* *}$ & 434.67 & & \\
\hline
\end{tabular}

*Body weight $(\mathrm{kg})$

**CD4 count (cells/ $\mu l)$

\section{DISCUSSION}

This study reported that most of the clients were males, were literate with the mean age of 36.8 years. Previous studies reported similar findings ${ }^{8,11,12}$ except the literacy rate which was much higher in these studies. Majority of the respondents had inadequate knowledge about HIV/AIDS which is contradictory to that reported by Olowookere et al. $(22.3 \%, \mathrm{n}=71)$ but similar to the findings of Lauren $\mathrm{M}(98.5 \%, \mathrm{n}=67$ vs $80 \%, \mathrm{n}=160)^{9,13}$. This difference was probably due to the high benchmark set for adequate knowledge in this study which was a score $\geq 75 \%$ but also refers to the dire need of HIV/AIDS education and counseling at the ART sites of Nepal. For instance, approximately one third of the respondents $(33.3 \%, 34.7 \%, 36.2 \%)$ respectively were actually aware of the transmittal of HIV via breastfeeding, could correctly define the term 'window period' and state its duration. This finding is in close agreement to the previous record ${ }^{12}$. However, the response rate of breastfeeding transmittance was reportedly higher than the data presented by Meena et al. $(2.9 \%, n=3)^{8}$.

Percentage of respondents voting for unsafe sex, blood transfusion and maternal to child transmission as the modes of transmission 
was comparatively lower than the reports of the preceding studies $[34.7 \%$ vs $99 \%(\mathrm{n}=198), 81 \%$ $(\mathrm{n}=258), 82 \%(\mathrm{n}=41)]$; [24.6\% vs $100 \%(\mathrm{n}=200)$, $91.2 \%(\mathrm{n}=290), \quad 64 \%(\mathrm{n}=32)]$ and $[11.5 \%$ vs $93.5 \%(\mathrm{n}=187), 22 \%(\mathrm{n}=11)]^{8,9,13}$. These findings are a strong indicator of the pressing need of education for PLHIV on the modes of transmission of HIV/AIDS as reports suggest knowledge about this is a critical determinant of the attitude about HIV/AIDS transmission ${ }^{2}$.

An absolute confusion was observed among the clients in regard to the understanding of the term 'viral load', probably indicating a mix up with another term 'CD4 count'. None of the clients was able to explain what viral load was and its significance in contrast to $35 \%(\mathrm{n}=70)$ and $55.7 \%(\mathrm{n}=177)$ in previous studies ${ }^{9,13}$. This indicates the lack of emphasis on the common terms as 'window period', 'viral load' and 'CD4 count' during counseling of HIV/AIDS clients. Only one third $(33.3 \%)$ of the respondents mentioned the right action to be taken in case of missed dose which is in line with the findings of Reginia $[14.4 \%(n=28)]$. A few alarming comments of consuming double doses in case of missed dose was received which is likely to initiate adverse drug reactions hence, further leading to noncompliance. Majority (52\%) believed skipping the missed dose would be the right thing to do which is one of the main causes of the emerging issue of antiretroviral resistance ${ }^{2}$. Some of the daunting responses to the action to be taken in case of running out of the prescription for ARV medication were doing nothing because he/she already took it for long enough $(50 \%)$ and wait till the next appointment $(11.5 \%)$ which would both lead to interruption in the treatment and drug resistance. Side effects reported by the patients in this study were no different than those stated by other authors ${ }^{2,14}$. An increase in CD4 count and weight gain was observed among the clients on ART which is in alignment with another study ${ }^{15}$.

No association was found between age, gender and knowledge score of the respondents similar to a previous literature ${ }^{16}$ whereas, a significant association was seen between education level and knowledge score which is in line with another study ${ }^{17}$.

\section{CONCLUSIONS}

The results suggest a dire need for a comprehensive educational approach for the ART clients on HIV/AIDS and their medication regimens.

\section{ACKNOWLEDGEMENTS}

We are indebted to NCASC and the ART sites for providing permission to conduct the study. We acknowledge the continuous support of Dr. Rajani Shakya, Head of Department of Pharmacy, Kathmandu University. We would also like to acknowledge all the participants who took part in this study.

\section{Conflict of interest}

The authors declare that they have no conflict of interests.

\section{Funding}

None to declare.

\section{Ethics approval}

Ethics approval to conduct the study was taken from the institutional review centre (IRC) of Dhulikhel Hospital (IRC approval number: 110/16).

\section{Article info:}

Received June 26, 2019

Accepted April 14, 2020

\section{REFERENCES}

1. Bam K, Rajbhandari RM, Karmacharya DB, Dixit SM. Strengthening adherence to Anti Retroviral Therapy (ART) monitoring and support: operation research to identify barriers and facilitators in Nepal. BMC Health Serv Res. 2015;15:188.

2. Almeida RF, Vieira AP. Evaluation of HIV/AIDS patients' knowledge on antiretroviral drugs. Braz J Infect Dis. 2009;13(3):183-90.

3. Arnsten JH, Demas PA, Farzadegan H, Grant RW, Gourevitch MN, Chang C et al. Antiretroviral Therapy Adherence and Viral Suppression in HIV Infected Drug Users: Comparison of Self-Report and Electronic Monitoring. Clin Infect Dis. 2001;33(8):1417-23.

4. Heestermans T, Browne JL, Aitken SC, Vervoort SC, Klipstein-Grobusch K. Determinants of adherence to antiretroviral therapy among HIV-positive adults in sub-Saharan Africa: a systematic review. BMJ Global Health. 2016;1(4):e000125

5. Johnson CJ, Heckman TG, Hansen NB, Kochman A, Sikkem KJ. Adherence to antiretroviral medication in older adults living with HIV/AIDS: a comparison of alternative models. AIDS Care. 2009;21(5):541-51.

6. Wutoh AK, Elekwachi O, Clarke-Tasker V, Daftary $\mathrm{M}$, Powell NJ, Campusano G. Assessment and Predictors of Antiretroviral Adherence in Older HIVInfected Patients. J Acquir Immune Defic Syndr. 2003;33:S106-14

7. Kip E, Ehlers VJ, van der Wal DM. Patients' adherence to antiretroviral therapy in Botswana. J Nurs Scholarsh. 2009;41(2):149-57.

8. Meena LP, Pandey SK, Rai M, Bharti A, Sunder S. Knowledge, attitude and practice (KAP) study on HIV/AIDS among HIV patients, care givers, and general population in north-eastern part of India. Int $\mathbf{J}$ 
Med Sci Pub Health. 2013;2(1):36-42.

9. Olowookere SA, Fatiregun AA, Akinyemi JO, Bamgboye AE, Osagbemi GK. Prevalence and determinants of nonadherence to highly active antiretroviral therapy among people living with HIV/AIDS in Ibadan, Nigeria. J Infect Developing Countries. 2008;2(5):369-72.

10. Kongnyuy EJ, Ngassa P, Fomulu N, Wiysonge CS, Kouam L, Doh AS. A survey of knowledge, attitudes and practice of emergency contraception among university students in Cameroon. BMC Emergency Medicine. 2007:7:7.

11. Cauldbeck MB, O'Connor C, O'Connor MB, Bamgboye AE, Osagbemi GK. Adherence to anti-retroviral therapy among HIV patients in Bangalore, India. AIDS Res Ther. 2009;6:7.

12. Zaheer MS, Rabbani MU, Ahmad Z, Khan T, Rewari BB, Pandey DK. Clinical and demographic profile of AIDS in and around Aligarh. J Indian Accad of Clin Medicine. 2003;4(2):121-6.
13. Terblanche LM, Stellenberg EL. Patient knowledge of HIV and its treatment in South Africa. African J Prim Health Care Fam Med. 2014;6(1):518.

14. Sapkota S, Shakya R, Pandey B. Study on Highly Active Anti-Retroviral Therapy: prescription pattern and side effects. JNPA. 2012;26(1):12-8.

15. Olawumi HO, Olatunji PO, Salami AK, Odeigah L, Iseniyi JO. Effect of highly active antiretroviral therapy on CD4 count and weight in AIDS patients seen at the UITHI, Ilorin. Niger J Clin Pract. 2008;11(4):312-5.

16. Shrestha S, Sapkota B, Kumpakha A, Acharya U, Sharma R. Evaluation of patients' knowledge on warfarin in outpatient pharmacy of a tertiary care cardiac center. BMC Res Notes. 2015;8:429.

17. Hasan SS, Shamala R, Syed IA, et al. Factors Affecting Warfarin-Related Knowledge and INR Control of Patients Attending Physician- and Pharmacist-Managed Anticoagulation Clinics. J Pharm Pract. 2011;24(5):485-93. 